\title{
Effect of new antioxidants: phenolipids on quality of fried French fries and rapeseed oil
}

\author{
Aleksandra Szydłowska-Czerniak ${ }^{1}$ (D) Dobrochna Rabiej ${ }^{1}$
}

Revised: 4 August 2020/ Accepted: 26 August 2020/Published online: 1 September 2020

(C) The Author(s) 2020

\begin{abstract}
The purpose of this work was to evaluate the effect of five novel synthetic antioxidants: octyl sinapate (OSA), octyl ferulate (OFA), octyl caffeate (OCA), cetyl sinapate (CSA) and cetyl ferulate (CFA) added to refined rapeseed oil for the first time on antioxidant activity (AA) and total phenolic content (TPC) in French fries. French fries after frying in enriched oils had higher the AA determined by three assays: 2,2'-azino-bis-3-ethylbenzothiazoline-6-sulfonic acid (ABTS $=2907-20,029 \mu \mathrm{mol}$ TE/100 g), 2,2-diphenyl-1-picrylhydrazyl $\quad$ (DPPH = 657-6886 $\mu \mathrm{mol} \mathrm{TE} / 100 \mathrm{~g}$ ), ferric reducing antioxidant power (FRAP $=332-2659 \mu \mathrm{mol} \mathrm{TE} / 100 \mathrm{~g}$ ) and total phenolic content $(\mathrm{TPC}=44-378 \mathrm{mg} \mathrm{SA} / 100 \mathrm{~g})$ than those prepared in refined rapeseed oil (ABTS $=2146 \mu \mathrm{mol}$ TE/ $100 \mathrm{~g}, \mathrm{DPPH}=403 \mu \mathrm{mol} \mathrm{TE} / 100 \mathrm{~g}$, FRAP $=218 \mu \mathrm{mol}$ $\mathrm{TE} / 100 \mathrm{~g}, \mathrm{TPC}=14 \mathrm{mg} \mathrm{SA} / 100 \mathrm{~g}$ ). Moreover, the presence of phenolipids in rapeseed oil decreased the oil content in fried French fries by $22-45 \%$. However, the AA and TPC in the fortified oils significantly increased, whereas slower changes in oxidation parameters of supplemented oils after frying were observed. A new lipophilic
\end{abstract}

Electronic supplementary material The online version of this article (https://doi.org/10.1007/s13197-020-04765-z) contains supplementary material, which is available to authorized users.

Aleksandra Szydłowska-Czerniak

olasz@umk.pl

1 Faculty of Chemistry, Nicolaus Copernicus University in Toruń, 7 Gagarin Street, 87-100 Toruń, Poland antioxidants can be useful for the development of management system for the preparation of French fries and the prolongation of frying oil shelf life.

Keywords Antioxidant activity · French fries - Rapeseed oil · Phenolipids · Oxidation parameters · Frying

\section{Introduction}

Frying is one of the most popular process of food preparation, wherein the food is cooked while floating or being immersed in hot oil. Unfortunately, high temperature and oxygen exposition during the frying resulting in oxidation, polymerization, degradation, hydrolysis, which produce a lot of nutritionally harmful compounds with negative impact on quality of oil and fried food.

A well-known synthetic (butylated hydroxytoluene, BHT, butylated hydroxyanisole, BHA, tertiary butyl hydroquinone, TBHQ) and various natural (tocopherols or other phenolic compounds) antioxidants are introduced to oils in order to retard their autoxidation and enhance the shelf life of fried products (Aydeniz and Yilmaz 2012). However, the addition of synthetic antioxidants is strictly regulated by governments due to the potential health risk of these compounds in foods. Therefore, the efficacy of natural antioxidants extracted from olive leaf, olive mill waste water, hazelnut leaf, hazelnut green leafy cover, wild rose hip, berries, fruits, herbs, spices, canola distillate, canola meal and rosemary for extension of shelf life of frying oils and fried products has been extensively studied (Aachary et al. 2014; Aladedunye et al. 2014; Aladedunye and Matthäus 2014; Aydeniz and Yilmaz 2012; Chiou et al. 2009; Matthäus et al. 2014; Redondo-Cuevas et al. 2017; Sordini et al. 2019). The supplementation of frying oils 
with natural antioxidants improved the quality of prepared food products due to the absorption of fats with active compounds during thermal treatment. French fries fried in rapeseed oils with purified native and lipophilized extracts from rowanberry and crabapple had higher content of tocopherols than those prepared in refined rapeseed oil without antioxidants (Aladedunye et al. 2015; Aladedunye and Matthäus 2016). Furthermore, French fries after frying in sunflower, palm and olive oils fortified with olive leaf extracts were richer source of polyphenols, tocopherols, phytosterols, squalene and exhibited higher antioxidant activity (AA) in comparison with control oil samples (Chiou et al. 2009).

However, the application of plants' antioxidants, mainly phenolic acids in oil-based food products are limited due to their low solubility in hydrophobic media. Recently, lipophilization of phenolic acids, especially through esterification with fatty alcohols has been a widely recognized method to enhance their solubility in non-aqueous media and applicability in foods containing oils and fats (Alemán et al. 2015; Menezes et al. 2011; Sørensen et al. 2014; Szydłowska-Czerniak et al. 2018). Moreover, the addition of the lipophilized phenolic compounds (phenolipids) to mixture of rapeseed and linseed oils, mayonnaise and milk enriched with fish oil significantly affected the antioxidant properties of enriched fat products (Alemán et al. 2015; Sørensen et al. 2015; Szydłowska-Czerniak et al. 2018). The antioxidative effect of synthesized phenolipids depended on their chemical structure (mainly the alkyl chain length), concentrations and type of real samples (bulk oil or emulsion).

Although oxidative stability and amounts of tocopherols and phytosterols in the fortified rapeseed oils during frying have widely been investigated, to the best of our knowledge there are no reports on the estimation of the impact of phenolipids added to frying medium on the AA of fried French fries, enriched rapeseed oil and fat uptake.

Therefore, the purpose of the present work was to investigate the effect of five novel synthetic antioxidants: octyl sinapate (OSA), octyl ferulate (OFA), octyl caffeate (OCA), cetyl sinapate (CSA) and cetyl ferulate (CFA) added to rapeseed oil on the antioxidant properties of fried French fries and absorbed oil as well as oil uptake during frying. Moreover, the changes in antioxidant potential and oxidative status of rapeseed oils without and with phenolipids before and after frying were estimated. The AA of the studied samples were determined by $2,2^{\prime}$ azinobis-3-ethylbenzothiazoline-6-sulfonic acid (ABTS), 2,2-diphenyl-1-picrylhydrazyl (DPPH) and ferric reducing antioxidant power (FRAP) methods, while total phenolic content (TPC) was analyzed by Folin-Ciocalteu (FC) assay.

\section{Material and methods}

\section{Reagents}

All reagents of analytical or HPLC grade were purchased from Sigma-Aldrich (Poznań, Poland).

\section{Chemical synthesis, purification and analysis of phenolipids}

The novel lipophilic antioxidants: OSA, OFA, OCA, CSA and CFA were synthesized by Fischer esterification following the procedure described in our previous report with some modifications (Szydłowska-Czerniak et al. 2018). In brief, to sinapic acid-SA (6 mmoL), ferulic acid-FA (6 mmoL) and caffeic acid-CA (6 mmoL) with 1-octanol (48, 24 and $66 \mathrm{mmoL}$ for SA, FA and CA, respectively) or 1-hexadecanol (66 and $33 \mathrm{mmoL}$ for SA and FA, respectively) dried over $3 \AA$ molecular sieves prior to reactions, in a two-neck flasks equipped with a magnetic stirring bar, reflux condenser and a thermometer, $25 \mu \mathrm{L}$ of the sulphuric acid solution in alcohol $(10 \mathrm{~mol} / \mathrm{L})$ was added during stirring. Moreover, activated molecular sieves $(3 \AA$, $40 \mathrm{mg} / \mathrm{mL}$ ) were introduced to the reaction mixtures to remove water formed during esterification. The reaction mixtures were stirred during the whole reaction time $(3 \mathrm{~h}$ for SA and FA and $2 \mathrm{~h}$ for CA) and incubated at $100{ }^{\circ} \mathrm{C}$. Reaction mixtures were cooled to room temperature, diluted with ethyl acetate (octyl esters) or tert-butyl methyl ether (cetyl esters), washed with brine and water (3 times) for removal of acids and dried over $\mathrm{MgSO}_{4}$. The solvents were evaporated under reduced pressure.

The synthesized octyl and cetyl esters (OSA, OFA, CSA and CFA) were purified by flash column chromatography on silica gel (pore size $60 \AA$, Kieselgel, Macherey-Nagel, Germany, column: $400 \mathrm{~mm}$ long $\times 20 \mathrm{~mm}$ in diameter, Witko, Poland) using as an eluent dichloromethane/ethyl acetate $=90: 10$, whereas OCA was purified by crystallization from heptane.

Qualitative analysis of the obtained phenolic acids esters was carried out by thin-layer chromatography (TLC) on pre-coated TLC-plates, silica gel 60 with fluorescent indicator UV254, trade name ALUGRAM R SIL G/UV 254 (Macherey-Nagel, Germany), using a dichloromethane/ ethyl acetate (90:10) as an eluent. The spots were visualized under a UV light detection (254 nm). Then TLC plates were sprayed with vanillin solution and heated at $150{ }^{\circ} \mathrm{C}$ for 5 min to detect octyl and cetyl esters.

Structures of the purified octyl and cetyl esters were confirmed by nuclear magnetic resonance (NMR) spectroscopy. ${ }^{1} \mathrm{H}$ and ${ }^{13} \mathrm{C}$ NMR spectra of the isolated esters were recorded at $700 \mathrm{MHz}$ and $170 \mathrm{MHz}$, respectively on a 
Bruker Avance III $700 \mathrm{MHz}$ spectrometer (Bruker Corporation, Karlsruhe, Germany) at $298 \pm 1 \mathrm{~K}$. The samples were dissolved in chloroform-d $\left(\mathrm{CDCl}_{3}\right)$ containing tetramethylsilane (TMS) as internal standard. Chemical shifts were recorded in $\delta$ values in parts per million (ppm) and coupling constant $(J)$ were reported in Hertz $(\mathrm{Hz})$.

The synthesized phenolic acids esters had the following characteristics:

OSA (octyl (E)-3-(4-hydroxy-3,5dimethoxyphenyl)propenoate)

Light yellow oil, ${ }^{1} \mathrm{H}$ NMR $\left(\mathrm{CDCl}_{3}\right): \delta 0.88(\mathrm{t}, J=7.0 \mathrm{~Hz}$, $3 \mathrm{H}), 1.23-1.36(\mathrm{~m}, 8 \mathrm{H}), 1.37-1.43(\mathrm{~m}, 2 \mathrm{H}), 1.66-1.73(\mathrm{~m}$, 2H), 3.91 (s, 6H), 4.19 (t, $J=6.8 \mathrm{~Hz}, 2 \mathrm{H}), 5.83$ (br. s., $1 \mathrm{H}$ ), $6.30(\mathrm{~d}, J=15.9 \mathrm{~Hz}, 1 \mathrm{H}), \quad 6.77 \quad(\mathrm{~s}, \quad 2 \mathrm{H}), 7.58 \quad(\mathrm{~d}$, $J=15.9 \mathrm{~Hz}, 1 \mathrm{H}) .{ }^{13} \mathrm{C} \mathrm{NMR}\left(\mathrm{CDCl}_{3}\right): \delta 13.80,22.38$, $25.75,28.52,29.01,31.55,56.02\left(2 \mathrm{xOCH}_{3}\right), 64.38,104.92$ $(2 \times \mathrm{CH}), 115.58,125.59,137.11,144.70,147.11(2 \times \mathrm{C})$, 167.09 .

\section{OFA (octyl (E)-3-(4-hydroxy-3-methoxy-phenyl)-2-} propenoate)

Light cream oil, ${ }^{1} \mathrm{H}$ NMR $\left(\mathrm{CDCl}_{3}\right): \delta 0.89(\mathrm{t}, J=7.1 \mathrm{~Hz}$, $3 \mathrm{H}), 1.24-1.37(\mathrm{~m}, 8 \mathrm{H}), 1.38-1.43(\mathrm{~m}, 2 \mathrm{H}), 1.67-1.73(\mathrm{~m}$, 2H), 3.92 (s, 3H), 4.20 (t, $J=6.7 \mathrm{~Hz}, 2 \mathrm{H}), 5.98$ (br. s., $1 \mathrm{H}$ ), $6.30(\mathrm{~d}, J=15.9 \mathrm{~Hz}, 1 \mathrm{H}), 6.92(\mathrm{~d}, J=8.2 \mathrm{~Hz}, 1 \mathrm{H}), 7.03$ $(\mathrm{d}, J=1.9 \mathrm{~Hz}, 1 \mathrm{H}), 7.07(\mathrm{dd}, J=8.2,1.9 \mathrm{~Hz}, 1 \mathrm{H}), 7.61(\mathrm{~d}$, $J=15.9 \mathrm{~Hz}, 1 \mathrm{H}) .{ }^{13} \mathrm{C} \mathrm{NMR}\left(\mathrm{CDCl}_{3}\right): \delta 14.00,22.58$, $25.94,28.72,29.13,29.19,31.73,55.86,64.57,109.36$, $114.73,115.58,122.95,126.98,144.62,146.79,147.93$, 167.38 .

\section{OCA (octyl (E)-3-(3,4-dihydroxyphenyl)-2-propenoate)}

White solid, ${ }^{1} \mathrm{H}$ NMR $\left(\mathrm{CDCl}_{3}\right): \delta 0.90(\mathrm{t}, J=7.2 \mathrm{~Hz}, 3 \mathrm{H})$, $1.24-1.37$ (m, 9H), 1.37-1.43 (m, 2H), 1.67-1.74 (m, 2H), 4.20 (t, $J=6.8 \mathrm{~Hz}, 2 \mathrm{H}$ ), 5.59 (br. s., $2 \mathrm{H}$ ), 6.28 (d, $J=15.9 \mathrm{~Hz}, 1 \mathrm{H}), 6.88(\mathrm{~d}, J=8.2 \mathrm{~Hz}, 1 \mathrm{H}), 7.03(\mathrm{dd}$, $J=8.2,1.9 \mathrm{~Hz}, 1 \mathrm{H}), 7.10(\mathrm{~d}, J=1.9 \mathrm{~Hz}, 1 \mathrm{H}), 7.58(\mathrm{~d}$, $J=15.9 \mathrm{~Hz}, 1 \mathrm{H}) .{ }^{13} \mathrm{C} \mathrm{NMR}\left(\mathrm{CDCl}_{3}\right): \delta 14.06,22.64$, 25.98, 28.74, 29.19, 29.24, 31.79, 64.75, 114.40, 115.57, $116.12,122.44,127.88,143.66,144.39,145.98,167.56$.

CSA (hexadecyl (E)-3-(4-hydroxy-3,5-

dimethoxyphenyl)propenoate)

Light yellow solid, ${ }^{1} \mathrm{H}$ NMR $\left(\mathrm{CDCl}_{3}\right): \delta \quad 0.84 \quad(\mathrm{t}$, $J=7.7 \mathrm{~Hz}, 3 \mathrm{H}), 1.22-1.31(\mathrm{~m}, 25 \mathrm{H}), 1.36-1.37(\mathrm{~m}, 2 \mathrm{H})$, $1.66-1.68(\mathrm{~m}, 2 \mathrm{H}), 3.88(\mathrm{~s}, 6 \mathrm{H}), 4.16(\mathrm{t}, J=7.0 \mathrm{~Hz}, 2 \mathrm{H})$, 5.88 (br. s., 1H), 6.27 (d, $J=16.1 \mathrm{~Hz}, 1 \mathrm{H}), 6.74(\mathrm{~s}, 2 \mathrm{H})$, $7.55(\mathrm{~d}, J=16.1 \mathrm{~Hz}, 1 \mathrm{H}) .{ }^{13} \mathrm{C}$ NMR $\left(\mathrm{CDCl}_{3}\right): \delta 14.06$,
$22.65, \quad 28.74, \quad 29.30-29.67 \quad\left(12 \quad \mathrm{CH}_{2}\right), \quad 31.89, \quad 56.15$ $\left(2 \mathrm{x} \times \mathrm{OCH}_{3}\right), \quad 64.54, \quad 104.99(2 \times \mathrm{CH}), 115.74,125.77$, $137.21,144.86,147.24(2 \times C), 167.20$.

CFA (hexadecyl (E)-3-(4-hydroxy-3-methoxy-phenyl)-2propenoate)

Light orange solid, ${ }^{1} \mathrm{H} \quad \mathrm{NMR} \quad\left(\mathrm{CDCl}_{3}\right): \delta \quad 0.88 \quad(\mathrm{t}$, $J=7.7 \mathrm{~Hz}, 3 \mathrm{H}), 1.25-1.31(\mathrm{~m}, 28 \mathrm{H}), 1.36-1.37(\mathrm{~m}, 2 \mathrm{H})$, $1.68-1.69(\mathrm{~m}, 2 \mathrm{H}), 3.93(\mathrm{~s}, 3 \mathrm{H}), 4.18(\mathrm{t}, J=14 \mathrm{~Hz}), 5.86$ br. s., $1 \mathrm{H}), 6.30(\mathrm{~d}, J=16.1 \mathrm{~Hz}, 1 \mathrm{H}), 6.91(\mathrm{~d}, 8.4 \mathrm{~Hz}, 1 \mathrm{H})$, $7.03(\mathrm{~d}, 2.1 \mathrm{~Hz}, \mathrm{~d}), 7.06(\mathrm{dd}, J=9.6,2.1 \mathrm{~Hz}, 1 \mathrm{H}), 7.59(\mathrm{~d}$, $J=16.1 \mathrm{~Hz}, 1 \mathrm{H}) .{ }^{13} \mathrm{C}$ NMR $\left(\mathrm{CDCl}_{3}\right): \delta 14.10,22.69$, $25.74,26.00,28.61,28.79,29.31,29.36,29.46,29.55$, $29.59,29.65,29.69,31.92,32.83,55.94,63.12,64.61$, $109.31,114.68,115.73,123.09,144.06,144.76,146.76$, 147.90, 167.37.

\section{Samples}

Refined rapeseed oil in the original package (1-L polyethylenterephthalate (PET) bottle) was kindly provided by a local vegetable oil factory. The frozen pre-fried French fries (Aviko brand, purchased from a local supermarket) were selected as the standard test food for frying due to their standard composition (an initial fat content $=4.0 \%$, protein $=2.5 \%$, carbohydrates $=24.5 \%$ ) and easy availability.

\section{Frying procedure}

Rapeseed oils enriched with OSA, OFA, OCA, CSA and CFA, respectively $\left(100.0 \mathrm{~g}\right.$ of oil, $\left.\mathrm{c}_{\text {phenolipid }}=0.5 \%\right)$ were poured into $250 \mathrm{~mL}$ glass beakers $(6.0 \mathrm{~cm}$ diameter) and heated up to $180 \pm 5^{\circ} \mathrm{C}$ on a hot plate for $10 \mathrm{~min}$. The oil temperature was checked by a digital thermometer. Then portion of $15.0 \pm 0.5 \mathrm{~g}$ of frozen French fries (approximately $9 \times 9 \times 30 \mathrm{~mm}$ ) was immersed into each oil and fried for $4 \mathrm{~min}$. After frying under domestic conditions, French fries were placed in a clean dry paper for $5 \mathrm{~min}$, allowing for the excess oil to drain. All frying experiments were performed in two repetitions using control and enriched rapeseed oils as well as frozen French fries. The fried oils in amber-colored bottles and fried French fries collected in aluminium foil were stored in refrigerator $\left(4^{\circ} \mathrm{C}\right)$ for 1 day until analysis.

\section{Determination of antioxidant activity and total phenolic content}

The AA and TPC in methanolic extracts of fortified rapeseed oils used as frying media, fried French fries and oils extracted from them were determined by modified 
spectrophotometric methods: ABTS, DPPH, FRAP and Folin-Ciocalteu (FC), respectively described in our previous report (Szydłowska-Czerniak and Łaszewska 2015).

The detailed procedures of samples preparation and the AA and TPC determination can be found in the supplementary data.

\section{Oil content in French Fries}

The oil from French fries was extracted three times by hexane using a Soxhlet apparatus. Briefly, the grounded French fries $(5.0 \mathrm{~g})$ were packed inside a cartridge, transferred to an extractor device and submitted to $3 \mathrm{~h}$ recycling extraction with $150 \mathrm{~mL}$ hexane at boiling temperature $\left(70{ }^{\circ} \mathrm{C}\right)$. The hexane-oil mixtures were heated to evaporate the solvent and the oil was weighted using an analytical balance. Yield of oil was expressed as:

\%oil content $=\frac{\text { weight of oil obtained after extraction }}{\text { weight of dry sample }}$
$\times 100$

\section{Analysis of oils oxidative status}

The refined and supplemented rapeseed oils before and after frying were characterized according to the official ISO methods by peroxide value (PV) (ISO 3960 2017), anisidine value (p-AnV) (ISO 6885 2016), acid value (AV) (ISO 660 2009), conjugated diene (CD) and conjugated triene (CT) values as the absorbance of $1 \%$ solution of each oil in hexane (no additional dilutions were made) at 233 and $268 \mathrm{~nm}$, respectively in a $1 \mathrm{~cm}$ quartz cell (ISO 3656 2011). The TOTOX was used as a characteristic value for total oxidation of triglycerides and was calculated by the expression: TOTOX $=(2 \mathrm{PV}+\mathrm{p}-\mathrm{AnV})$.

\section{Statistical analysis}

The AA and TPC in oils before and after frying, French fries and oils extracted from them were determined five times within 1 day by the modified ABTS, DPPH, FRAP and FC methods. The oil content in French fries as well as oxidation parameters: $\mathrm{PV}, \mathrm{p}-\mathrm{AnV}, \mathrm{AV}$ and amounts of $\mathrm{CD}$ and $\mathrm{CT}$ in each oils before and after frying were analyzed in triplicate. The obtained results were presented as: mean (c) \pm standard deviation (SD). One-way analysis of variance (ANOVA), followed by the Duncan test, was performed to analyze the significant differences between data $(p<0.05)$.

\section{Results and discussion}

\section{Antioxidant activity and total phenolic content in frying oils and French Fries}

The AA determined by three analytical methods was the highest for rapeseed oil with OCA and the lowest for control oil without antioxidants (Table 1).

Furthermore, the AA results revealed that octyl esters had significantly higher antioxidant potential than cetyl esters. Therefore, the ABTS, DPPH and FRAP values of rapeseed oils enriched with octyl esters were more than two times higher than those for rapeseed oils fortified with cetyl esters (Table 1, Duncan test).

Nevertheless, the FRAP and DPPH of oil with phenolipids changed significantly during frying process, whereas ABTS of oils with OCA and CSA did not differ significantly before and after frying (Table 1, Duncan test). This indicated that the hydrophilic antioxidants determined by FRAP assay and these hydrophobic compounds available to react with the DPPH radical were not thermally stable and were reduced during frying, but the fried oils were all time in contact with the most sensitive components of French fries (vitamins, phenolics and other antioxidants), which can affected total antioxidant potential of oils. The supplementation of rapeseed oil with OSA resulted in a more effective protection of hydrophobic antioxidants against their decomposition (the lowest DPPH decrease was observed for oil with OSA after frying). However, OCA can be the most protective against both hydrophilic and hydrophobic antioxidants (the ABTS of oil with OCA insignificantly reduced after frying).

On the contrary, Duncan test indicated that the AA of oils fortified with OFA, CSA and CFA significantly increased after frying (Table 1). This fact can be explained as that both cetyl esters and OFA probably retarded degradation of antioxidants naturally present in rapeseed oil as well as bioactive compounds from French fries, which contact with fortified oils during frying. Moreover, cetyl esters could be less thermally stable under the drastic conditions than octyl esters and easily hydrolized to corresponding phenolic acids having a high antioxidant potential.

It can be noted that frying in oils without phenolipids and with OSA and OCA reduced TPC in the studied oils by about $17-42 \%$, whereas oils enriched with CSA and CFA contained approximately 1.3 times higher amount of phenolics after processing (Table 1). It is known that thermal treatment of oil causes a decrease in phenolics content, but the presence of cetyl esters and endogenous phenolics in rapeseed oil and French fries can enhance their relative stability. The Duncan test indicated that, frying in rapeseed 
Table 1 Antioxidant activity and total phenolic content in the refined (RO) and enriched rapeseed oils before (BF) and after (AF) frying process

\begin{tabular}{|c|c|c|c|c|}
\hline Oil sample & $\begin{array}{l}\text { ABTS }^{*} \pm \text { SD } \\
(\mu \mathrm{mol} \mathrm{TE} / 100 \mathrm{~g})\end{array}$ & $\begin{array}{l}\mathrm{DPPH}^{*} \pm \mathrm{SD} \\
(\mu \mathrm{mol} \mathrm{TE} / 100 \mathrm{~g})\end{array}$ & $\begin{array}{l}\mathrm{FRAP}^{*} \pm \mathrm{SD} \\
(\mu \mathrm{mol} \mathrm{TE} / 100 \mathrm{~g})\end{array}$ & $\begin{array}{l}\mathrm{TPC}^{*} \pm \mathrm{SD} \\
(\mathrm{mg} \mathrm{SA} / 100 \mathrm{~g})\end{array}$ \\
\hline BF-RO & $905 \pm 42^{\mathrm{a}}$ & $322 \pm 3^{\mathrm{a}}$ & $296 \pm 11^{\mathrm{b}}$ & $12 \pm 0.5^{\mathrm{a}}$ \\
\hline AF-RO & $806 \pm 33^{\mathrm{a}}$ & $313 \pm 14^{\mathrm{a}}$ & $227 \pm 4^{\mathrm{a}}$ & $10 \pm 0.4^{\mathrm{a}}$ \\
\hline BF-RO + OSA & $13,850 \pm 633^{g}$ & $3794 \pm 93^{\mathrm{h}}$ & $980 \pm 21^{\mathrm{i}}$ & $167 \pm 4^{g}$ \\
\hline $\mathrm{AF}-\mathrm{RO}+\mathrm{OSA}$ & $12,328 \pm 239^{\mathrm{f}}$ & $3505 \pm 115^{g}$ & $817 \pm 37^{\mathrm{h}}$ & $138 \pm 5^{\mathrm{f}}$ \\
\hline $\mathrm{BF}-\mathrm{RO}+\mathrm{OFA}$ & $9406 \pm 132^{\mathrm{d}}$ & $2870 \pm 96^{\mathrm{e}}$ & $557 \pm 6^{\mathrm{f}}$ & $134 \pm 3^{\mathrm{f}}$ \\
\hline $\mathrm{AF}-\mathrm{RO}+\mathrm{OFA}$ & $10,063 \pm 281^{\mathrm{e}}$ & $3209 \pm 86^{\mathrm{f}}$ & $646 \pm 24^{g}$ & $136 \pm 5^{\mathrm{f}}$ \\
\hline $\mathrm{BF}-\mathrm{RO}+\mathrm{OCA}$ & $15,621 \pm 591^{h}$ & $7628 \pm 247^{\mathrm{j}}$ & $3327 \pm 34^{\mathrm{k}}$ & $607 \pm 17^{\mathrm{i}}$ \\
\hline $\mathrm{AF}-\mathrm{RO}+\mathrm{OCA}$ & $15,266 \pm 538^{h}$ & $6374 \pm 107^{\mathrm{i}}$ & $1658 \pm 20^{\mathrm{j}}$ & $351 \pm 12^{\mathrm{h}}$ \\
\hline $\mathrm{BF}-\mathrm{RO}+\mathrm{CSA}$ & $6434 \pm 109^{\mathrm{b}, \mathrm{c}}$ & $1792 \pm 22^{\mathrm{c}}$ & $439 \pm 21^{\mathrm{e}}$ & $69 \pm 3^{\mathrm{d}}$ \\
\hline $\mathrm{AF}-\mathrm{RO}+\mathrm{CSA}$ & $6584 \pm 122^{\mathrm{b}, \mathrm{c}}$ & $2600 \pm 118^{\mathrm{d}}$ & $676 \pm 20^{g}$ & $86 \pm 4^{\mathrm{e}}$ \\
\hline $\mathrm{BF}-\mathrm{RO}+\mathrm{CFA}$ & $6146 \pm 170^{\mathrm{b}}$ & $1493 \pm 26^{\mathrm{b}}$ & $340 \pm 13^{\mathrm{c}}$ & $34 \pm 1^{\mathrm{b}}$ \\
\hline $\mathrm{AF}-\mathrm{RO}+\mathrm{CFA}$ & $6832 \pm 222^{\mathrm{c}}$ & $1842 \pm 69^{c}$ & $375 \pm 16^{\mathrm{d}}$ & $45 \pm 2^{c}$ \\
\hline
\end{tabular}

$*_{n}=5$; $S D$ standard deviation; Different letters $(\mathrm{a}-\mathrm{k})$ within the same column indicate significant differences between AA and TPC in oils

oil with OFA did not affect significantly TPC, which was similar to this found in the fried rapeseed oil with OSA. Also, TPC in control oil did not change significantly during frying.

For comparison, sunflower $\left(\mathrm{IC}_{50}=13.2-65.3 \mathrm{mg}\right)$, olive $\left(\mathrm{IC}_{50}=12.5-35.1 \mathrm{mg}\right)$ and palm $\left(\mathrm{IC}_{50}=19.9-69.1 \mathrm{mg}\right)$ oils enriched with olive leaf extract revealed higher DPPH values than control samples $\left(\mathrm{IC}_{50}=91.3-98.9 \mathrm{mg}\right.$, 30.9-40.7 mg and 75.2-139.4, respectively) before and after frying. Although the quantities of all fried oils needed to decrease the initial DPPH radical concentration to $50 \%$ were higher than for fresh oils (Chiou 2009). Furthermore, rapeseed oils supplemented with olive leaf, hazelnut leaf and hazelnut green leafy cover extracts had higher ABTS results $(168.2,109.9$ and $199.8 \mu \mathrm{mol} \mathrm{TE} / \mathrm{g})$ at the end of frying than control sample (56.3-103.9 $\mu \mathrm{mol} \mathrm{TE} / \mathrm{g})$ in the all frying days. However, TPC in rapeseed oils with olive leaf and hazelnut green leafy cover extracts ranged between 2 and $8 \mathrm{mg} / 100 \mathrm{~g}$ and $1-6 \mathrm{mg} / 100 \mathrm{~g}$, respectively until the end of 7 days frying at $180{ }^{\circ} \mathrm{C}$, while phenolics were lost in rapeseed oil enriched with hazelnut leaf extract. Although the same amounts of phenolics remained in oil with hazelnut green leafy cover extract after first and seventh day of frying (Aydeniz and Yilmaz 2012). The concentrations of total phenolics in several oils decreased after frying at $180{ }^{\circ} \mathrm{C}$. However, lower differences in TPC were noted for soybean oil with rosemary $(28 \%)$ than in control oil sample (39\%) (Saoudi et al. 2016).

Rapeseed oils without and with five synthesized phenolipids were used to evaluate the effect of frying media on the AA and TPC in French fries. The obtained results of ABTS, DPPH, FRAP and TPC in French fries are listed in Table 2.
The AA of fried French fries ranged between 2146 and 20,029 $\mu \mathrm{mol}$ TE/100 g, 403-6886 $\mu \mathrm{mol} \mathrm{TE} / 100 \mathrm{~g}$ and 218-2659 $\mu \mathrm{mol}$ TE/100 $\mathrm{g}$ for the ABTS, DPPH and FRAP assays, respectively. Nevertheless, TPC determined by the FC method was the lowest for French fries prepared in refined rapeseed oil (14 $\mathrm{mg} \mathrm{SA} / 100 \mathrm{~g}$ ) and the highest for fries fried in rapeseed oil fortified with OCA (378 mg SA/ $100 \mathrm{~g}$ ). As expected, higher antioxidant potential of oil used for frying increased the AA and TPC in French fries (Tables 1 and 2). French fries fried in the supplemented oils revealed approximately 2-27 times higher AA and TPC results than those prepared in the refined rapeseed oil. Therefore, the frying medium significantly affected the AA and TPC in French fries (Table 2, Duncan test). This can be explained by the retention of antioxidants by French fries processed in oils enriched with phenolipids. The AA of French fries is composite mixture of all antioxidants from fries together with those from frying oil, because a part of oil is absorbed by fries during frying. However, antioxidants degraded under heating conditions, thus the AA of French fries is not sum of antioxidants found in oil and fries. Insignificant differences in ABTS and FRAP results were observed between French fries fried in rapeseed oils with ferulic acid esters, whereas the DPPH of fries prepared in oils containing CSA, OSA and OFA did not differ significantly (Table 2, Duncan test).

Similar effect of olive leaf extract added to sunflower, olive and palm oils on the DPPH and TPC in French fries was demonstrated by Chiou et al. (2007, 2009). French fries fried in supplemented sunflower, olive and palm oils had higher AA $\quad\left(\mathrm{EC}_{50}=19.9-37.7,15.2-32.0\right.$ and 31.5-174 mg) and TPC (19.3-23.2, 13.8-15.2 and 9.1-11.1 $\mathrm{mg} / 100 \mathrm{~g}$, respectively) than the respective ones prepared in non-supplemented oils $\left(\mathrm{EC}_{50}=57.2\right.$, 54.0 and 
Table 2 Antioxidant activity and total phenolic content in French fries fried in different media: refined (RO) and enriched rapeseed oils

\begin{tabular}{|c|c|c|c|c|}
\hline $\begin{array}{l}\text { Frying } \\
\text { medium }\end{array}$ & $\begin{array}{l}\text { ABTS }^{*} \pm \mathrm{SD}(\mu \mathrm{mol} \mathrm{TE} / \\
100 \mathrm{~g})\end{array}$ & $\begin{array}{l}\mathrm{DPPH}^{*} \pm \mathrm{SD}(\mu \mathrm{mol} \mathrm{TE} / \\
100 \mathrm{~g})\end{array}$ & $\begin{array}{l}\text { FRAP }^{*} \pm \mathrm{SD}(\mu \mathrm{mol} \mathrm{TE} / \\
100 \mathrm{~g})\end{array}$ & $\mathrm{TPC}^{*} \pm \mathrm{SD}(\mathrm{mg} \mathrm{SA} / 100 \mathrm{~g})$ \\
\hline RO & $2146 \pm 28^{\mathrm{a}}$ & $403 \pm 6^{\mathrm{a}}$ & $218 \pm 8^{\mathrm{a}}$ & $14 \pm 0.6^{\mathrm{a}}$ \\
\hline $\mathrm{RO}+\mathrm{OSA}$ & $4992 \pm 176^{\mathrm{c}}$ & $980 \pm 18^{\mathrm{c}, \mathrm{d}}$ & $612 \pm 26^{\mathrm{d}}$ & $172 \pm 3^{\mathrm{e}}$ \\
\hline $\mathrm{RO}+\mathrm{OFA}$ & $2907 \pm 99^{\mathrm{b}}$ & $903 \pm 16^{\mathrm{c}}$ & $385 \pm 19^{\mathrm{b}}$ & $96 \pm 0.5^{\mathrm{c}}$ \\
\hline $\mathrm{RO}+\mathrm{OCA}$ & $20,029 \pm 871^{\mathrm{d}}$ & $6886 \pm 205^{\mathrm{e}}$ & $2659 \pm 123^{\mathrm{e}}$ & $378 \pm 4^{\mathrm{f}}$ \\
\hline $\mathrm{RO}+\mathrm{CSA}$ & $3409 \pm 169^{\mathrm{b}}$ & $1046 \pm 33^{\mathrm{d}}$ & $527 \pm 19^{\mathrm{c}}$ & $141 \pm 5^{\mathrm{d}}$ \\
\hline $\mathrm{RO}+\mathrm{CFA}$ & $3263 \pm 49^{\mathrm{b}}$ & $657 \pm 29^{\mathrm{b}}$ & $332 \pm 4^{\mathrm{b}}$ & $44 \pm 1^{\mathrm{b}}$ \\
\hline
\end{tabular}

$*_{n}=5 ; S D$ standard deviation; Different letters (a-f) within the same column indicate significant differences between AA and TPC in French fries fried in different media

$454 \mathrm{mg}, \quad$ while $\quad \mathrm{TPC}=7.8, \quad 9.4$ and $8.2 \mathrm{mg} / 100 \mathrm{~g}$, respectively).

The analytical procedures for determinations of AA and TPC in French fries and oils before and after frying process do not significantly differ in their precisions (the relative standard deviation (RSD) results varied between $1.30-4.96 \%, 0.93-4.54 \%, 1.02-4.94 \%$, and $0.52-4.65 \%$ for ABTS, DPPH, FRAP and FC methods respectively), thus the proposed methods can be applied for reliable assessment of total antioxidant potential and phenolics content in the studied samples.

\section{Quantity and antioxidant activity of oil absorbed by French Fries}

The amount of oil absorbed by fried products is a critical parameter of their quality. As seen, the type of frying medium had a significant effect on the evolution of oil uptake in French fries (Fig. 1, Duncan test).

High fat content in the fried French fries (15.7-28.4\%) can be explained by the fact that frozen French fries were used for frying. Freezing increased the fat absorption due to lower amount of water in the frozen samples. Moreover, higher oil content in frozen samples after frying indicates that freezing temperature damaged their structures and enhanced fat absorption (Adedeji and Ngadi 2018). Oil content was the highest in French fries processed in the refined rapeseed oil without phenolipids $(28.4 \%)$. Oil uptake was importantly reduced $(22-45 \%)$ when phenolipids were added to oil. It is noteworthy that the lowest and similar oil absorption revealed French fries prepared in oils supplemented with OCA, OSA and CFA (Fig. 1). Probably, these phenolipids were more thermally stable and effectively reduced the dehydration of French fries. The hydrating effect of antioxidants added to frying medium facilitated starch gelatinization, improving structure formation and decreasing oil uptake by French fries.

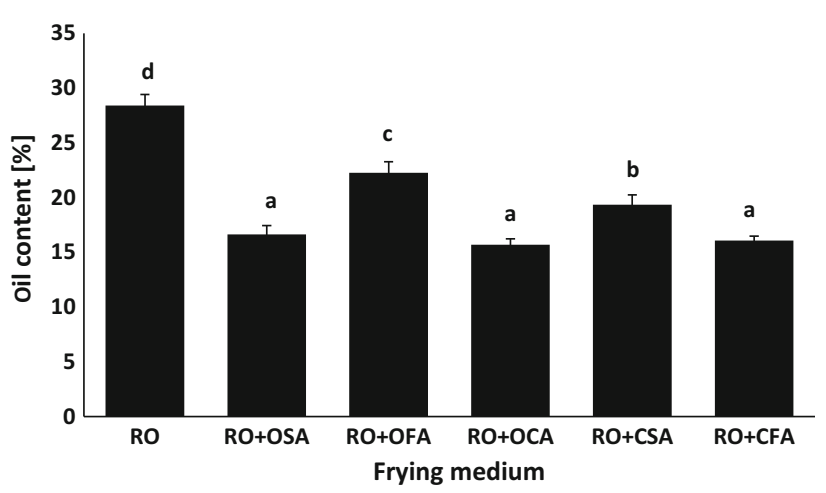

Fig. 1 Oil absorption during frying of French fries in different frying media: refined (RO) and enriched rapeseed oils. Different letters in the superscripts mean significant differences between used frying medium

Interestingly, the ABTS, DPPH, FRAP and TPC results of oils extracted from French fries after frying in rapeseed oil without phenolipids, with CSA and CFA were about 1.3-3.3 times higher than AA and TPC in these three oils used for frying (Tables 1 and 3).

However, oils absorbed by French fries had significantly lower AA (4-78\%) and TPC (about 60\%) than fried oils with octyl esters. This suggests that cetyl esters had a higher ability for dissolving of antioxidants present in French fries and supplemented oils when compared to octyl esters. Probably, the addition of cetyl esters enhanced the retention of antioxidant compounds in oils and their diffusion rate from fries to the extracted oil. On the other hand, oil extracted from French fries fried in refined rapeseed oil revealed significantly lower values of AA and TPC then those obtained from fries prepared in the fortified rapeseed oils (Table 3, Duncan test). This can be explained by the fact that phenolipids introduced to oil were capable to protect the bioactive compounds present in French fries and improve their retention.

In addition, the Duncan test indicated that the extracted oils from fries processed in rapeseed oils with OSA and 
Table 3 Antioxidant activity and total phenolic content in oils extracted from French fries fried in different media: refined (RO) and enriched rapeseed oils

\begin{tabular}{|c|c|c|c|c|}
\hline $\begin{array}{l}\text { Frying } \\
\text { medium }\end{array}$ & $\begin{array}{l}\mathrm{ABTS}^{*} \pm \mathrm{SD}(\mu \mathrm{mol} \mathrm{TE} / \\
100 \mathrm{~g})\end{array}$ & $\begin{array}{l}\mathrm{DPPH}^{*} \pm \mathrm{SD}(\mu \mathrm{mol} \mathrm{TE} / \\
100 \mathrm{~g})\end{array}$ & $\begin{array}{l}\text { FRAP* } \pm \text { SD }(\mu \mathrm{mol} \mathrm{TE} / \\
100 \mathrm{~g})\end{array}$ & $\begin{array}{l}\mathrm{TPC}^{*} \pm \mathrm{SD}(\mathrm{mg} \mathrm{SA} / \\
100 \mathrm{~g})\end{array}$ \\
\hline RO & $2304 \pm 96^{\mathrm{a}}$ & $443 \pm 14^{\mathrm{a}}$ & $386 \pm 15^{\mathrm{a}}$ & $20 \pm 0.7^{\mathrm{a}}$ \\
\hline $\mathrm{RO}+\mathrm{OSA}$ & $8946 \pm 284^{\mathrm{d}}$ & $3354 \pm 44^{\mathrm{e}}$ & $1234 \pm 20^{\mathrm{c}}$ & $145 \pm 7^{\mathrm{d}}$ \\
\hline $\mathrm{RO}+\mathrm{OFA}$ & $2857 \pm 50^{\mathrm{b}}$ & $697 \pm 28^{\mathrm{b}}$ & $402 \pm 5^{\mathrm{a}}$ & $42 \pm 1^{\mathrm{b}}$ \\
\hline $\mathrm{RO}+\mathrm{OCA}$ & $6050 \pm 206^{\mathrm{c}}$ & $2491 \pm 96^{\mathrm{c}}$ & $1148 \pm 52^{\mathrm{b}}$ & $134 \pm 6^{\mathrm{c}}$ \\
\hline $\mathrm{RO}+\mathrm{CSA}$ & $9447 \pm 446^{\mathrm{e}}$ & $3425 \pm 89^{\mathrm{e}}$ & $1329 \pm 21^{\mathrm{d}}$ & $143 \pm 1^{\mathrm{d}}$ \\
\hline $\mathrm{RO}+\mathrm{CFA}$ & $8633 \pm 211^{\mathrm{d}}$ & $3137 \pm 136^{\mathrm{d}}$ & $1232 \pm 16^{\mathrm{c}}$ & $131 \pm 5^{\mathrm{c}}$ \\
\hline
\end{tabular}

$*_{n}=5 ; S D$ standard deviation; Different letters (a-e) within the same column indicate significant differences between AA and TPC in oils from French fries fried in different media

CFA did not differ significantly in the ABTS and FRAP results. Insignificant differences in the DPPH and TPC were found between oils absorbed after frying in rapeseed oils with SA esters. Also, there were no significant differences in FRAP for oils extracted from fries fried in rapeseed oils without phenolipids and with OFA, as well as values of TPC for oils absorbed after frying in oils with OCA and CFA (Table 3, Duncan test).

Although there is a lack of information in the literature about the changes in the AA and TPC in oils extracted from food products after frying, some authors estimated the effects of olive leaf, hazelnut leaf and hazelnut green leafy cover added to sunflower, olive, palm and canola oils on oil content in the fried French fries and dough (Aydeniz and Yilmaz 2012; Chiou et al. 2007, 2009). Addition of phenolics from olive leaf to sunflower and olive oils reduced the oil amount in French fries by $3-16 \%$, whereas French fries after frying in enriched palm oil had higher fat content $(14.2-15.5 \mathrm{~g} / 100 \mathrm{~g})$ than those prepared in palm oil without phenolics (11.6 g/100 g) (Chiou et al. 2007, 2009). Moreover, the oil uptake in dough after the first three days frying in canola oils fortified with olive and hazelnut leaf extracts was higher than in refined canola oil, while dough fried the fourth and fifth day contained lower fat (Aydeniz and Yilmaz 2012).

\section{Oxidation state of frying oils}

It is known that the consumption of products from oxidized oils poses a chronic threat to human health. For this reason, the oxidation state of rapeseed oils with novel antioxidants after frying of French fries was estimated by analyzing amounts of primary (PV, CD, CT) and secondary (p-AnV) oxidation products, free fatty acids content (AV) and total oxidation (TOTOX) index (Table 4).

It is noteworthy that the unheated rapeseed oil revealed the lowest $\mathrm{PV}=0.08$ meq $\mathrm{O}_{2} / \mathrm{kg}$ and $\mathrm{p}-\mathrm{AnV}=1.51$, while the addition of phenolipids caused an increase in amounts of hydroperoxides ( $\mathrm{PV}=0.12-1.59 \mathrm{meq} \mathrm{O}_{2} / \mathrm{kg}$ ) and compounds with aldehyde carbonyl bond ( $\mathrm{p}-\mathrm{AnV}=1.54-1.78$ ) in rapeseed oil. The $\mathrm{PV}$ and $\mathrm{p}-\mathrm{AnV}$ of oils before frying were below the maximum values $\left(\mathrm{PV}<5 \mathrm{meq} \mathrm{O}_{2} / \mathrm{kg}\right.$ and p-AnV < 8) permitted for vegetable oils according to the ISO 3960 (2017) and ISO 6885 (2016). However, the heated rapeseed oils without esters and with OSA and OCA presented PV above the legal limit (6.37-11.24 meq $\mathrm{O}_{2} /$ $\mathrm{kg}$ ). The use of novel antioxidants significantly decreased the PV of oils after frying $\left(\mathrm{PV}=3.73-7.69 \mathrm{meq} \mathrm{O}_{2} / \mathrm{kg}\right)$ when compared to the control oil ( $\mathrm{PV}=11.24$ meq $\mathrm{O}_{2} / \mathrm{kg}$ ). Moreover, p-AnV of all fried rapeseed oils were approximately 5 times higher than for oils before frying (Table 4). A slower increase of $\mathrm{PV}$ and $\mathrm{p}-\mathrm{AnV}$ for the fortified rapeseed oils compared to a non-fortified oil indicates the effectiveness of novel antioxidants in delaying the oil oxidation. The changes in PV during frying of French fries depended on type of phenolipid added to oil, however oils with CFA and OSA oxidized at a slower rate. The PV of refined rapeseed oil and after addition of OCA and CSA were not significantly changed (Table 4, Duncan test). Furthermore, similar content of primary oxidation products was determined in oils fortified with OSA and CFA as well as in the fried oils with cetyl esters. As seen, the addition of each phenolipid to rapeseed oil did not significantly change the content of secondary oxidation products in the enriched oils (Table 4, Duncan test). Insignificant differences in p-AnV were also observed between oils with OFA, CSA and CFA after frying.

Additionally, the significant increase in total oxidation (high values of TOTOX) was found in all oils during frying. The control rapeseed oil and oil with OCA were more oxidized than oils stabilized with other phenolipids (Table 4). This can be explained by lower amount of natural antioxidants in control sample, causing its high oxidation state, whereas OCA was less thermally stable compared to the other esters. In addition, the Duncan 
Table 4 Oxidation parameters of the refined (RO) and enriched rapeseed oils before (BF) and after (AF) frying process

\begin{tabular}{|c|c|c|c|c|c|c|}
\hline Oil sample & $\mathrm{PV}^{*} \pm \mathrm{SD}\left(\right.$ meq $\left.\mathrm{O}_{2} / \mathrm{kg}\right)$ & $\mathrm{p}-\mathrm{AnV}^{*} \pm \mathrm{SD}$ & TOTOX & $\mathrm{CD}^{*} \pm \mathrm{SD}$ & $\mathrm{CT}^{*} \pm \mathrm{SD}$ & $\mathrm{AV}^{*} \pm \mathrm{SD}(\mathrm{mg} \mathrm{NaOH} / \mathrm{g})$ \\
\hline BF-RO & $0.08 \pm 0.002^{\mathrm{a}}$ & $1.51 \pm 0.07^{\mathrm{a}}$ & $1.67^{\mathrm{a}}$ & $2.606 \pm 0.125^{\mathrm{a}}$ & $0.489 \pm 0.018^{\mathrm{a}}$ & $0.015 \pm 0.0003^{\mathrm{a}}$ \\
\hline AF-RO & $11.24 \pm 0.11^{\mathrm{h}}$ & $8.74 \pm 0.26^{\mathrm{e}}$ & $31.22^{h}$ & $2.837 \pm 0.048^{\mathrm{b}}$ & $0.672 \pm 0.030^{\mathrm{b}}$ & $0.049 \pm 0.002^{\mathrm{b}}$ \\
\hline $\mathrm{BF}-\mathrm{RO}+\mathrm{OSA}$ & $1.54 \pm 0.06^{\mathrm{c}}$ & $1.63 \pm 0.05^{\mathrm{a}}$ & $4.71^{\mathrm{c}}$ & $3.001 \pm 0.043^{\mathrm{c}}$ & $0.930 \pm 0.043^{\mathrm{d}}$ & $0.130 \pm 0.004^{\mathrm{f}}$ \\
\hline $\mathrm{AF}-\mathrm{RO}+\mathrm{OSA}$ & $6.37 \pm 0.04^{\mathrm{f}}$ & $7.28 \pm 0.29^{\mathrm{b}}$ & $20.02^{f}$ & $3.200 \pm 0.034^{\mathrm{e}, \mathrm{f}}$ & $1.139 \pm 0.008^{\mathrm{f}}$ & $0.250 \pm 0.005^{\mathrm{j}}$ \\
\hline $\mathrm{BF}-\mathrm{RO}+\mathrm{OFA}$ & $0.42 \pm 0.01^{\mathrm{b}}$ & $1.64 \pm 0.06^{\mathrm{a}}$ & $2.48^{\mathrm{b}}$ & $3.121 \pm 0.044^{\mathrm{d}, \mathrm{e}}$ & $1.007 \pm 0.038^{\mathrm{e}}$ & $0.110 \pm 0.004^{\mathrm{e}}$ \\
\hline $\mathrm{AF}-\mathrm{RO}+\mathrm{OFA}$ & $3.73 \pm 0.10^{\mathrm{d}}$ & $7.91 \pm 0.11^{\mathrm{c}}$ & $15.37^{\mathrm{d}}$ & $3.282 \pm 0.042^{\mathrm{f}}$ & $1.135 \pm 0.005^{\mathrm{f}}$ & $0.260 \pm 0.002^{\mathrm{k}}$ \\
\hline $\mathrm{BF}-\mathrm{RO}+\mathrm{OCA}$ & $0.19 \pm 0.009^{\mathrm{a}}$ & $1.54 \pm 0.01^{\mathrm{a}}$ & $1.92^{\mathrm{a}}$ & $3.087 \pm 0.010^{\mathrm{c}, \mathrm{d}}$ & $1.573 \pm 0.052^{\mathrm{i}}$ & $0.150 \pm 0.003^{\mathrm{g}}$ \\
\hline $\mathrm{AF}-\mathrm{RO}+\mathrm{OCA}$ & $7.69 \pm 0.21^{\mathrm{g}}$ & $8.41 \pm 0.25^{\mathrm{d}}$ & $23.79^{\mathrm{g}}$ & $3.229 \pm 0.048^{\mathrm{f}}$ & $2.037 \pm 0.015^{\mathrm{j}}$ & $0.240 \pm 0.004^{\mathrm{i}}$ \\
\hline $\mathrm{BF}-\mathrm{RO}+\mathrm{CSA}$ & $0.12 \pm 0.003^{\mathrm{a}}$ & $1.78 \pm 0.05^{\mathrm{a}}$ & $2.02^{\mathrm{a}}$ & $3.070 \pm 0.006^{\mathrm{c}, \mathrm{d}}$ & $0.857 \pm 0.032^{\mathrm{c}}$ & $0.060 \pm 0.001^{\mathrm{c}}$ \\
\hline $\mathrm{AF}-\mathrm{RO}+\mathrm{CSA}$ & $4.85 \pm 0.07^{\mathrm{e}}$ & $7.81 \pm 0.20^{\mathrm{c}}$ & $17.51^{\mathrm{e}}$ & $3.246 \pm 0.014^{\mathrm{f}}$ & $0.979 \pm 0.016^{\mathrm{e}}$ & $0.130 \pm 0.006^{\mathrm{f}}$ \\
\hline $\mathrm{BF}-\mathrm{RO}+\mathrm{CFA}$ & $1.59 \pm 0.04^{\mathrm{c}}$ & $1.73 \pm 0.05^{\mathrm{a}}$ & $4.91^{\mathrm{c}}$ & $3.081 \pm 0.017^{\mathrm{c}, \mathrm{d}}$ & $1.365 \pm 0.011^{\mathrm{g}}$ & $0.080 \pm 0.002^{\mathrm{d}}$ \\
\hline $\mathrm{AF}-\mathrm{RO}+\mathrm{CFA}$ & $4.90 \pm 0.07^{\mathrm{e}}$ & $8.07 \pm 0.13^{\mathrm{c}}$ & $17.87^{\mathrm{e}}$ & $3.212 \pm 0.036^{\mathrm{f}}$ & $1.457 \pm 0.034^{\mathrm{h}}$ & $0.170 \pm 0.005^{\mathrm{h}}$ \\
\hline
\end{tabular}

$*_{n}=3 ; S D$ standard deviation; Different letters $(\mathrm{a}-\mathrm{k})$ within the same column indicate significant differences between oxidation parameters of oils

test indicated that there were significant differences between the effectiveness of the added octyl esters in retarding the deterioration process of oils during frying (Table 4).

On the other hand, CD and CT values, which represent the degree of production of the primary oxidation products in control rapeseed oil differed significantly from those determined for oils with phenolipids (Table 4, Duncan test). An increase in CD and CT amounts for control oil (8.1 and $27.2 \%$, respectively) at the end of frying was higher than that for oils with synthesized antioxidants (4.1-6.2\% and 6.3-22.8\% for CD and CT, respectively). Although the supplementation with five different esters did not significantly affect the CD values of unheated and heated oils (Table 4, Duncan test).

As seen, the thermal oxidation and hydrolysis reactions induced by water introduced with French fries caused the decomposition of triglycerides into free fatty acids (FFA), resulting in the significant $\mathrm{AV}$ increase during the frying process (Table 4, Duncan test). All the studied oils before and after frying had AV $(0.015-0.260 \mathrm{mg} \mathrm{NaOH} / \mathrm{g})$ below desirable level $(\mathrm{AV}<0.300 \mathrm{mg} \mathrm{NaOH} / \mathrm{g}$ ) for refined oil. Unexpectedly, addition of phenolipids increased the AV of fortified oils, suggesting that these esters probably promoted the hydrolysis reactions and FFA production.

Also Matthäus et al. (2014) found higher concentration of FFA (0.36-1.00 g/100 g) in rapeseed oils supplemented with rosemary extracts and canolol than AV $(0.10-0.60 \mathrm{~g} /$ $100 \mathrm{~g}$ ) of the fried rapeseed oil without antioxidants.

Although oils with cetyl esters had two times lower AV when compared to the AV of oils with octyl esters. However, an increase in AV during frying was significantly reduced (from $70 \%$ to $38-58 \%$ ) after addition of novel antioxidants to oil. Hence, phenolipids can be used as additives for increasing the stability of the fried oils.

It is noteworthy that, the addition of phenolipids unexpectedly induced primary and secondary oxidation products formation in fresh rapeseed oil. Probably, intensive mixing of oils with antioxidants during enrichment caused an increase in PV, p-AnV, AV and level of conjugated polyenes. Moreover, the synthesized cinnamate derivatives strongly absorbed in the UVA (400-315 nm) and UVB $(315-280 \mathrm{~nm})$ regions of the electromagnetic spectra. Therefore, the official spectrophotometric methods with low-cost, more available instrument, high precision $(\mathrm{RSD}=0.65-4.64,0.20-4.80$ and $0.44-4.62 \%$ for $\mathrm{p}-\mathrm{AnV}$, $\mathrm{CD}$ and CT, respectively, Table 4), but lower sensitivity due to overlapping peaks characteristic for added antioxidants and oxidation products were used for simple monitoring of oxidation products in the fortified oils. Absorbance at $268 \mathrm{~nm}$ provides a measure of the CT content, however the band at $270 \mathrm{~nm}$ for caffeates and ferulates corresponds to a mixture of $n \rightarrow \pi^{*}$ and $\pi \rightarrow \pi^{*}$ transitions (it consists of a charge transfer from the carboxylate and the carbonaceous chain toward the benzene ring) (Horbury et al. 2017).

It seems that CFA was the most efficient in the inhibition of generation of primary oxidation products in oil during frying, whereas OCA can be considered as more effective than others esters for FFA reduction in the heated rapeseed oil. However, the highest inhibitory effect on the formation of secondary oxidation products during frying determined as p-AnV was observed in the CSA and OSA (Table 4).

For comparison, rapeseed oils enriched with different natural (native phloridzin from Canadian crabapple, 
extracts from Rosa woodsii hip, Sorbus aucuparia and Malus baccata berries, rosemary, canolol as well as canola oil deodistillates) and synthetic (phloridzyl octadecanoate, dihydrocaffeic acid amides, BHT and TBHQ) antioxidants revealed significantly lower $\mathrm{PV}=110-279 \mu \mathrm{M}, \mathrm{p}-\mathrm{AnV}=$ 25-201, TOTOX $=100-994, \mathrm{CD}=1.00-4.19$ and $\mathrm{CT}=$ 0.22-1.14 after frying process than oils without antioxidants $(\mathrm{PV}=120-831 \mu \mathrm{M}, \mathrm{p}-\mathrm{AnV}=100-224$, TOTOX = 390-1778, CD = 1.50-4.64 and CT = 0.39-3.18) (Aachary et al. 2014; Aladedunye et al. 2014; Aladedunye and Matthäus 2014, 2016; Aladedunye and Przybylski 2014; Matthäus et al. 2014; Redondo-Cuevas et al. 2017).

\section{Conclusion}

The presence of novel antioxidants in rapeseed oil affected the antioxidant potential of fried French fries and oil uptake. The enrichment of rapeseed oil with phenolipidsoctyl and cetyl esters of phenolic acids enhanced the AA and TPC in French fries. French fries during frying in the fortified oils absorbed lower amount of oil with higher AA and TPC.

Generally cetyl esters strongly inhibited the formation of oxidation products in rapeseed oil during frying under domestic conditions. However, oils fortified with octyl esters had higher antioxidant potential before and after frying process than oils with cetyl esters. Therefore, future activities should mainly focus on investigations of changes in the quality of fried products and oils enriched with phenolipds during continuous frying, which is industrially important food process.

Moreover, it is crucial to evaluate potential toxic effect of phenolipids added to oil-based foods and identify the impact of different processes such as frying and storage under various conditions that can be responsible for their toxicity.

Acknowledgments Dobrochna Rabiej wishes to thank Polish National Science Center for the financial support: grant no. 2018/29/ N/NZ9/02748

Open Access This article is licensed under a Creative Commons Attribution 4.0 International License, which permits use, sharing, adaptation, distribution and reproduction in any medium or format, as long as you give appropriate credit to the original author(s) and the source, provide a link to the Creative Commons licence, and indicate if changes were made. The images or other third party material in this article are included in the article's Creative Commons licence, unless indicated otherwise in a credit line to the material. If material is not included in the article's Creative Commons licence and your intended use is not permitted by statutory regulation or exceeds the permitted use, you will need to obtain permission directly from the copyright holder. To view a copy of this licence, visit http://creativecommons. org/licenses/by/4.0/.

\section{References}

Aachary AA, Chen Y, Eskin NAM, Thiyam-Hollander U (2014) Crude canolol and canola distillate extracts improve the stability of refined canola oil during deep-fat frying. Eur J Lipid Sci Technol 116:1467-1476. https://doi.org/10.1002/ejlt.201300498

Adedeji AA, Ngadi M (2018) Impact of freezing method, frying and storage on fat absorption kinetics and structural changes of parfried potato. J Food Eng 218:24-32. https://doi.org/10.1016/j. jfoodeng.2017.08.024

Aladedunye F, Kersting HJ, Matthäus B (2014) Phenolic extract from wild rose hip with seed: composition, antioxidant activity, and performance in canola oil. Eur $\mathrm{J}$ Lipid Sci Technol 116:1025-1034. https://doi.org/10.1002/ejlt.201300255

Aladedunye F, Matthäus B (2014) Phenolic extracts from Sorbus aucuparia (L.) and Malus baccata (L.) berries: antioxidant activity and performance in rapeseed oil during frying and storage. Food Chem 159:273-281. https://doi.org/10.1016/j. foodchem.2014.02.139

Aladedunye F, Matthäus B (2016) Effective lipophilic antioxidant enzymatically derived from Canadian crabapple. Eur J Lipid Sci Technol 118:919-927. https://doi.org/10.1002/ejlt.201500299

Aladedunye F, Niehaus K, Bednarz H, Thiyam-Hollander U, Fehling E, Matthäus B (2015) Enzymatic lipophilization of phenolic extract from rowanberry (Sorbus aucuparia) and evaluation of antioxidative activity in edible oil. LWT - Food Sci Technol 60:56-62. https://doi.org/10.1016/j.lwt.2014.08.008

Aladedunye F, Przybylski R (2014) Phosphatidylcholine and dihydrocaffeic acid amide mixture enhanced the thermo-oxidative stability of canola oil. Food Chem 150:494-499. https://doi.org/ 10.1016/j.foodchem.2013.10.165

Alemán M, Bou R, Guardiola F, Durand E, Villeneuve P, Jacobsen Ch, Sørensen A-DM (2015) Antioxidative effect of lipophilized caffeic acid in fish oil enriched mayonnaise and milk. Food Chem 167:236-244. https://doi.org/10.1016/j.foodchem.2014. 06.083

Aydeniz B, Yilmaz E (2012) Enrichment of frying oils with plant phenolic extracts to extend the usage life. Eur J Lipid Sci Technol 114:933-941. https://doi.org/10.1002/ej1t.201100228

Chiou A, Kalogeropoulos N, Salta FN, Efstathiou P, Andrikopoulos NK (2009) Pan-frying of French fries in three different edible oils enriched with olive leaf extract: oxidative stability and fate of microconstituents. LWT Food Sci Technol 42:1090-1097. https://doi.org/10.1016/j.lwt.2009.01.004

Chiou A, Salta FN, Kalogeropoulos N, Mylona A, Ntalla I, Andrikopoulos NK (2007) Retention and distribution of polyphenols after pan-frying of French fries in oils enriched with olive leaf extract. J Food Sci 72:574-584. https://doi.org/10. 1111/j.1750-3841.2007.00493.x

Horbury MD, Baker LA, Rodrigues NDN, Quan W-D, Stavros VG (2017) Photoisomerization of ethyl ferulate: a solution phase transient absorption study. Chem Phys Lett 673:62-67. https:// doi.org/10.1016/j.cplett.2017.02.004

International Organization for Standardization ISO 3656 (2011) Animal and vegetable fats and oils-determination of ultraviolet absorbance expressed as specific UV extinction. Switzerland, Geneva

International Organization for Standardization ISO 3960 (2017) Animal and vegetable fats and oils-determination of peroxide value-iodometric (visual) endpoint determination. Switzerland, Geneva

International Organization for Standardization ISO 660 (2009) Animal and vegetable fats and oils-determination of acid value and acidity. Switzerland, Geneva 
International Organization for Standardization ISO 6885 (2016) Animal and vegetable fats and oils-determination of anisidine value. Switzerland, Geneva

Matthäus B, Pudel F, Chen Y, Achary A, Thiyam-Hollander U (2014) Impact of canolol-enriched extract from heat-treated canola meal to enhance oil quality parameters in deep-frying: a comparison with rosemary extract and TBHQ-fortified oil systems. J Am Oil Chem Soc 91:2065-2076. https://doi.org/10.1007/s11746-0142561-8

Menezes JCJMDS, Kamat SP, Cavaleiro JAS, Gaspar A, Garrido J, Borges F (2011) Synthesis and antioxidant activity of long chain alkyl hydroxycinnamates. Eur J Med Chem 46:773-777. https:// doi.org/10.1016/j.ejmech.2010.12.016

Redondo-Cuevas L, Castellano G, Raikos V (2017) Natural antioxidants from herbs and spices improve the oxidative stability and frying performance of vegetable oils. Int $\mathrm{J}$ Food Sci Technol 52:2422-2428. https://doi.org/10.1111/ijfs.13526

Saoudi S, Chammem N, Sifaoui I, Bouassida-Beji M, Jiménez IA, Bazzocchi IL, Silva SD, Hamdi M, Bronze MR (2016) Influence of Tunisian aromatic plants on the prevention of oxidation in soybean oil under heating and frying conditions. Food Chem 212:503-511. https://doi.org/10.1016/j.foodchem.2016.05.186

Sordini B, Veneziani G, Servili M, Esposto S, Selvaggini R, Lorefice A, Taticchi A (2019) A quanti-qualitative study of a phenolic extract as a natural antioxidant in the frying processes. Food Chem 279:426-434. https://doi.org/10.1016/j.foodchem.2018. 12.029

Sørensen A-DM, Durand E, Laguerre M, Bayrasy Ch, Lecomte J, Villeneuve P, Jacobsen Ch (2014) Antioxidant properties and efficacies of synthesized alkyl caffeates, ferulates, and coumarates. J Agric Food Chem 62:12553-12562. https://doi.org/10. 1021/jf500588s

Sørensen A-DM, Lyneborg KS, Villeneuve P, Jacobsen Ch (2015) Alkyl chain length impacts the antioxidative effect of lipophilized ferulic acid in fish oil enriched milk. J Funct Food 18:959-967. https://doi.org/10.1016/j.jff.2014.04.008

Szydłowska-Czerniak A, Łaszewska A (2015) Effect of refining process on antioxidant capacity, total phenolics and prooxidants contents in rapeseed oils. LWT Food Sci Technol 64:853-859. https://doi.org/10.1016/j.lwt.2015.06.069

Szydłowska-Czerniak A, Rabiej D, Krzemiński M (2018) Synthesis of novel octyl sinapate to enhance antioxidant capacity of rapeseed-linseed oil mixture. J Sci Food Agric 98:1625-1631. https://doi.org/10.1002/jsfa.8637

Publisher's Note Springer Nature remains neutral with regard to jurisdictional claims in published maps and institutional affiliations. 